\title{
MORAL VALUES IN HAYAO MIYAZAKI'S SPIRITED AWAY: A SOCIOLOGY OF LITERATURE APPROACH
}

\author{
Fajria Noviana \\ Japanese Language and Culture Department, Faculty of Humanities, Diponegoro University, \\ Semarang, Indonesia
}

fajria.noviana@live.undip.ac.id

\begin{abstract}
Moral is what guides human to act humanly. That is why moral education should be taught as early as possible in order to make a society that upholds moral values. This paper focused on moral values of the Japanese that can be seen in Miyazaki's anime entitled Spirited Away. The moral values discussed in this paper are based on Japanese moral education for elementary school level, which divided into four groups of desirable habits. They are matters belonging to oneself, relationship of self to other persons, matters related chiefly to nature and sublime things, and matters concerning the group and society. The determination of this level is due to the behavior of the main character named Chihiro who was an elementary school student, which is used as a guide to discussing moral values consisted in the anime. The conclusion is that the Japanese government has succeeded in giving moral education in elementary school, at least in this anime. Chihiro's actions are proof that she acts and reacts as what she taught in Japanese elementary school. She did exactly the same with recommended traits in the four groups of desirable habits, although she sometimes broke the rules which was natural for human being, especially for kids. Therefore, we can say that well-structured Japanese moral education can be used in much wider place; not only in Japan but also in other countries.
\end{abstract}

Keywords: moral values; moral education; Japanese; anime

\section{Introduction}

Traditional Japanese education aims at perfection of character through the development of mental, moral and physical development. Individually, each is referred as cognitive development, development or virtue and physical development. Collectively, they are called three developments. Among the three core developments, moral education addressing development of virtue has attracted much attention from scholars and educators, whether in or outside the country (Anzai, 2014).
Early in the Meiji Restoration, moral education taught in public and private schools in Japan. Systems of moral and spiritual values are transmitted in family and society. Some of them are based on religious beliefs or traditions. Religion and moral concepts stemming from religious faith in private and public life, and influence on the teaching of morality. And at the end of Meiji Era, teachers were encouraged to enforce strict discipline as a part of Confucianist moral concepts, as an implementation of moral education (Luhmer, 1990). 
As Luhmer has stated, starting from 1958 and has undergone several revisions, moral education for the elementary school is divided into three sections of objectives; one set for first/second, third/fourth, and fifth/sixth grades (Luhmer, 1990). Each of these sections is subdivided into four groups of desirable habits, as shown below:

1) Matters belonging to oneself

2) Relationship of self to other persons

3) Matters related chiefly to nature and sublime things (life, beauty)

4) Matters concerning the group and society (truthfulness, respect for parents and grandparents, teachers, good relations with classmates, etc.)

These sections in the junior high school have no further division by grades, leaving more freedom for teachers to organize the subject matter. In his paper, Luhmer stated that traits recommended under every heading are subdivided into another four groups (Luhmer, 1990) as shown below:

1) Truthfulness, sincerity, selfrespect, self-advancement, etc.

2) Politeness, warm personal relations, friendship, respect for the other sex, humble readiness to learn from others, etc.

3) Foster a sense of reverence for that which transcends human powers

4) Self-reliance, respect for the law, social solidarity and justice, love of labor, and cultivation of the family spirit

From the perspective of the sociology of literature, moral education and moral values as part of the social reality of society are often represented in literary works, because literary work is one of what society produce, i.e. lullaby. As we all know, lullaby meant to soothe babies, regardless of the meaning of their words, because lullaby possess a peaceful hypnotic quality. One of the earliest lullabies on record, dating from around $2,000 B C$ is deeply etched into a small clay tablet ("The universal language of lullabies - BBC News," n.d.). A rather modern lullaby usually contains moral education or moral values in its lyrics. For an example is the Itsy-Bitsy Spider lyrics ("Lullaby lyrics: ItsyBitsy Spider | BabyCenter," n.d.) as written below:
The itsy-bitsy spider
Climbed up the water spout
Down came the rain
And washed the spider out
Out came the sun
And dried up all the rain
And the itsy-bitsy spider
Climbed up the spout again

The lullaby above encourages children to have fighting spirits since their early stage, no matter what the obstacles are. This message conveyed through the spider's effort to climbed up to the water spout again, after that tiny little spider has washed down by the rain.

As mentioned in previous paragraph, literary work is one of what society produce. This statement has brought us to Swingewood's statement, regarding the sociology of literature. According to him, the study of sociology of literature connects the factors that exist in the social environment of society outside of literary works with those in literary works (Swingewood \& Laurenson, 1972). Sociology of literature itself is a piece of knowledge to understand literary works 
that use sociology as an assistive knowledge, so the study of sociology of literature is actually an interdisciplinary study.

As an interdisciplinary study, it requires an understanding of matters inside and outside the literary works that have been studied, related to what the focus on research's theme, before we can use the sociology of literature itself. Thus, since this paper discusses moral values in anime, then knowledge about moral, as mentioned at the beginning of this section, and about anime is needed. Anime selected as research corpus for this paper because anime as a popular literary work is generally more acceptable at various age levels of audiences than any classical literary works.

When hearing the word 'anime', most of people might tend to think that it is exactly the same as animation. We cannot say that such an assumption is wrong, but actually anime has its significant differences from animation. Anime focuses on the design of characters and settings whereas animation pays more attention to motions and movements. The content and the subject matter of anime are also different from animation. Anime targets different age groups, not restricted to just children. Since it has adult audiences as well, anime can also deal with serious and complex subject matter. Mature content that may include sex and violence can also be seen in anime. Besides of its content, one cannot simply classified anime as a children's film only, because according to Street, children's film is merely an adaptation result of classic children's literary work (Noviana, 2018).

When watching anime, first time viewers may hit by the performances' embrace of unreality. Heavily stylized, in a mixture of unreal and real components, fanciful worlds are created before us. Through the mixture of accurate imitation and imaginative lyricism, this practice has resulted in the distinct aesthetic arts of Noh, Bunraku, Kabuki. The balance between realism and (conventionalized) stylization is a defining characteristic of the three Japanese theatrical forms as well as anime. This is most apparent in the medium of anime itself. The entirety of the animated form is completely fabricated and manipulated (Suan, 2013). But, as a literary work, it still has messages and moral values.

This paper focused on the moral values of the Japanese that can be seen in Miyazaki's anime entitled Spirited Away (Miyazaki, 2001). The moral values discussed in this paper are based on Japanese moral education for elementary school level that was explained in the previous paragraph. The determination of this level is due to the behavior of the main character named Chihiro who was an elementary school student, which is used as a guide to discussing moral values consisted of the anime. The reason of using the main character for this study is described in the next paragraph.

People use to treat the characters of play or novel as though they were actual people, which almost impossible to avoid (Eagleton, 2013). A character was a sign, portrait or description of what a man or woman was like. Then, after a while, it came to mean the man or woman as such. The word 'character' is thus an example of the figure of speech known as synecdoche, in which a part represents the whole. The shift from character as the peculiar mark of an individual to character as the individual himself is bound up with the social history. It belongs to the rise of modern individualism. Individuals are now defined by what is peculiar to them, such as their signature or inimitable personality. What 
distinguishes us from each other is more important than what we have in common. Today, the term 'character' means an individual's mental and moral qualities (Eagleton, 2013). Therefore, based on Eagleton's statements about characters, then using Chihiro as the main character of Spirited Away suits this study that focused on moral values of the Japanese.

The original title of this Studio Ghibli's production anime is Sen to Chihiro no Kamikakushi. This anime tells the story of the struggle of Chihiro Ogino, a little girl who was just an elementary school student, to save her father and mother who were cursed into pigs when their family accidentally entered the world of the spirits. For most Westerners, the unclear distinction between boundaries of reality and dream might create discomfort, even though in East Asian tradition such boundaries allowed to be more fluid (Napier, 2019). The anime has won a lot of prize, including Best Animated Feature Film in 75th Annual Academy Awards and Golden Bear prize in 2002 Berlin International Film Festival.

Regarding many prizes it won, Spirited Away has been used, and maybe will still be used, as a data resource in many types of research. For example, journal article titled Hayao Miyazaki's Mythic Poetic: Experiencing the Narrative Persuasions in Spirited Away, Howl's Moving Castle and Ponyo. This article aims to look into the narrative renderings and the plot of Hayao Miyazaki's animated feature films. Miyazaki's stories may be regarded as modern mythic narratives and some of the cases discussed are rendered as archetypal. The conclusion is that for Miyazaki, anime is a creative frame in which he mobilizes semiotic contents, whether drawn from traditional Japanese Shinto beliefs of animism, myths, or the material imagination of water and space (Wu, 2016).

There is also a thesis titled The Anima in Animation: Miyazaki's Heroines and Post-Patriarchal Consciousness that discusses heroines in several anime works by Miyazaki, one of which is Spirited Away. The conclusion is Miyazaki's heroines clearly different from Hollywood's standard. The heroines in anime are alive and richly working within the psyche of the character. A non-anime heroine is one that is disabled and disempowered or warlike and rapacious so that she is either passive or combative throughout the storyline (Shore, 2014).

Meanwhile, one example of research on Japanese moral values is a journal article titled Religion, Moral Values and the Ethics of Japanese Society. The conclusion is risk of discrimination towards non-Japanese people living in Japanese society because the social obligation on the Japanese to be 'decent' and 'fair' towards the non-Japanese is not as strong as it is towards other Japanese (Ghotbi, 2015).

Previous research on moral values in anime, including those using Spirited Away as a data source, has been done quite a lot. But researches that based on moral values in the curriculum on moral education in Japan at the elementary school level was not found. Meanwhile, the purpose of this paper is to reveal the moral values contained in Miyazaki's Spirited Away, based on the moral education curriculum at the Japanese elementary school level.

\section{Research Method}

This research design uses qualitative methods. Data collected in the form of 
events that related to the actions of main character Chihiro in the research corpus, which is Miyazaki's Spirited Away anime, while recommended traits in the four groups of desirable habits as mentioned previously is used as a reference. Data collection using observation and record technique, while the data analysis uses the sociology of literature design.

Chihiro's actions treated as data, selected by which contains moral values based on a moral education curriculum for elementary school students in Japan. Those data then compared with the three sections of objectives in moral education for the elementary school which each of them has desirable habits and recommended traits, so that conclusions can be drawn. To facilitate the readers for better understanding, below is a synopsis of the Spirited Away.

\section{Synopsis}

Chihiro Ogino is a whiny pessimistic tenyear-old girl who is annoyed about having to move to a new town. Chihiro was not happy with the move, so that all the way to her new home, she looked pensive and depressed.

While driving to their new house, Chihiro's father attempts to follow a shortcut, but they subsequently lose their way. Within the next minute, this family come across a mysterious tunnel which leads to spirits world, with seemingly empty restaurants. Then Chihiro's father and mother eat food they found in one restaurant, even though Chihiro had warned them not to eat it.

When his parents were busy eating, Chihiro followed the village road and came to a large bridge that led to a very large public bath house. On the bridge she met
Haku, a boy who looked about her age. Haku asked Chihiro to leave the place with her family immediately before dusk, but it was too late. Chihiro's parents who had devoured many large amounts of food in one restaurant greedily, had turned into very large pigs and did not recognize her. The spirits in the form of large black shadows who apparently the villagers began to appear. Chihiro who was frightened then tried to return to her car but she was blocked by the sea, which she and her family passed before was a meadow.

Chihiro's distress at losing her parents is compounded by the discoveries that the world around her has changed, and that her body seems to disappear slowly. Haku appears and comforts Chihiro, and gives her a berry to eat, so that her body returns to normal. Haku then tells Chihiro to work for Yubaba, a witch who owns the public bath house in that spirits world. Thus, Chihiro could have the opportunity to help her parents who were cursed into pigs by Yubaba for their greediness.

During Chihiro's adventures in the spirits world, she was greatly assisted not only by Haku, but also by Kamaji and Rin. Kamaji is a demon spider in the form of an old man who has six very long arms which can extend up to several meters, and two feet. Meanwhile, Rin is a ghost in the form of a pretty young girl. In addition to these three, there are also Kaonashi and Bou characters. Kaonashi is a ghost in the form of a black shadow that has no face, so he always wears a mask. Bou, which is Yubaba's child, is a giant baby. Another character who only appears in the final quarter of the story is Zeniba, Yubaba's twin sister who's also a witch. Zeniba gave Chihiro a talisman in the form of a hair tie, 
so that she can break free from the effect of Yubaba's spell.

Chihiro, who was later employed by Yubaba in the public bath house, had forgotten her true identity, after her name was changed to Sen by Yubaba. Apparently, it was Yubaba's way to make anyone who worked for her subdued and could not leave that place forever.

Chihiro went through various obstacles and tests that threatened her life in the spirits world, in order to save her parents and Haku. Apparently, Haku turned out to be the Kohaku River Spirit who once rescued Chihiro, who had fallen into the Kohaku River when she was just a baby. Unfortunately, the Kohaku River has long been drained for housing construction, so Haku has no place to return. At the end of the story, Chihiro managed to save Haku and her parents. Chihiro then returned to the human world with her father and mother. But they have no memory about what happened.

\section{Findings and Discussion}

The results of the analysis of moral values are presented in four sections altogether with the discussion, as described below.

\section{Matters belonging to oneself}

Recommended traits for this point are truthfulness, sincerity, self-respect, selfadvancement, etc.

The truthfulness of Chihiro can be seen when she faced the angry Kaonashi, when nobody else dare to. Instead of saying things to calm him down, Chihiro bravely said that she cannot accompany him at that moment, as Kaonashi asked it from her, because she has to go to some place to save Haku, whose life is endangered. Hearing that, Kaonashi get angrier that he even tried to swallow her. Even though, Chihiro still tried to help Kaonashi to release his anger, so he can be back to who he used to be; a calm and kind-hearted spirit. From this scene, we can see the sincerity of Chihiro toward Kaonashi.

Not only toward Kaonashi, we can also feel and see Chihiro's sincerity toward Haku, when she cried and tried with all her might to save his life. Haku almost died because of Yubaba, who threw him into the well of predatory spirits, since Yubaba thought he is no longer useful for her. When Chihiro saw that, without any hesitance she held Haku's body, which at that moment in the form of white dragon, to prevent him from falling down into the well of predatory spirits that causing her to fell into the well, too. Chihiro even gave him half of the herbal medicine she received from another river spirit, though that herbal medicine was meant to heal her parents, so they could be human again.

Through the adventure, we can see that Chihiro has grown from a whiny pessimistic and cowardly little girl into a brave and confident one. This is a proof that she has the self-advancement point. In some way, this point respond to what I mentioned in my previous paper about Chihiro; she has undergone a total of the twelve stages of Vogler's hero's journey theory. Her adventure has succeeded in changing her personality to be brave, independent, calm and confident, and full of compassion. Her heroic journey proves the true definition of a hero according to Vogler, whilst also prove that to win a fight does not always use physical strength. There are times when thinking intelligence and emotional intelligence are much more needed (Noviana, 2019). 


\section{Relationship of self to other persons}

Recommended traits for this point are politeness, warm personal relations, friendship, respect for the other sex, humble readiness to learn from others, etc.

We can see Chihiro's politeness from how she acts towards those spirits she encountered. Chihiro always bows to whoever she meets, even though she doesn't really like the person or the spirit. She also bows to ask for forgiveness whenever she is done something wrong. This bow is called ojigi, the Japanese way of greeting as an essential part of Japanese culture. Ojigi is a sign of respect given by the person bowing to the person bowed before. It is also common when showing gratitude or apologizing. For example, Chihiro's first ojigi in the spirits world is when she met Kamaji for the first time. She bows to introduce herself then ask Kamaji for a job there. She also bows to any other spirit she met, whether she knows them or not.

Then, Chihiro's warm personal relations can be seen in how she treated other spirits, and vice versa. Chihiro always acts nicely to others, and in return, they act nicely to her too, even though some of them were being mean in the first place. For example is Bou, Yubaba's big baby. At their accidentally first met, Bou forced Chihiro to play with him, because he was bored of playing alone. He even threatened Chihiro to break her hand if she doesn't obey. Instead of felt angry to Bou, Chihiro acted nicely to Bou in their next met. She even allowed him to go along with her to Zeniba, his mother's twin sister.

In the spirit world, Chihiro has made friends with a lot of spirits who work in the bath house, the customers, Bou, and Zeniba. Amongst them, she made a very close friendship with Rin and Kamaji, and especially Haku. Rin and Kamaji helped Chihiro a lot during her stay and work in the bath house. But between Chihiro and Haku, we can tell that they both willing to sacrifice their selves in order to help and to protect each other. From these friendships and how she acts to others, we can also tell that Chihiro respects all of them, not discriminated them by their sex, their position, nor their species.

From know nothing what to do, Chihiro has transformed herself into a good decision maker in most of her time in the spirit world. Ever since Chihiro succeeded in making Yubaba decided to work her in the bath house, Chihiro has learned one thing that she never learned before as a spoiled child, which is working hard to get something you have really wanted. She had to restrain her fear, her pessimistic way of thinking, and had to learn things in the hard way to free her parents from Yubaba's hand. She learned this from her everyday interactions with Haku, Rin, Kamaji, and other spirits who worked in the bath house.

We can see how she tried hard to beat her own fear from climbing down the frail wooden ladder to reach Kamaji's place which stretched down along the cliff, as Haku told her; how she tried hard to follow instructions from Rin about cleaning bathroom; and how she restrained herself from arguing Yubaba's order to satisfy the customer, even it was the most stinky spirit.

\section{Matters related chiefly to nature and sublime things}

Recommended traits for this point are foster a sense of reverence for that which transcends human powers.

Human usually succumb to something with power that transcends 
human power, i.e. the force of nature, which delivered human to respect it. But in this anime, Chihiro as a human at first respect the power of supernatural beings, as some of the spirits have scary look, and that hers and her parents' life hanging on a thread that held by Yubaba. But gradually, her fears for them turned into honest respect, as she saw that they are not one hundred percent evil, yet some of them even have a sense of humanity. For examples are Yubaba and Bou, who at first being mean to Chihiro but later got softer on her.

\section{Matters concerning the group and society}

Recommended traits are self-reliance, respect for the law, social solidarity and justice, love of labor, and cultivation of the family spirit.

The self-reliance of Chihiro can be seen from how she tried hard to save her parents, who have always been the closest people she depended on. Her dependence on Haku and Rin also getting lower, after she felt she can firmly stand on the ground by herself. This all happened when she started to work in the bath house, where she met various obstacles in her everyday life. For examples are the intimidated Yubaba, the indifferent frog-foreman, the turned-greedy Kaonashi, and the bath house workers who looked down on her. None of them has weakened her. In fact, Chihiro made it as starting point to less depending on other people's help.

With less dependence on other people's help, Chihiro became more mature and made her give all her efforts to work in the bath house. For example is to clean the bathroom and to satisfy the customer at her best. We can see this in the scene when a river spirit came to the bath house with stinky mud covered his body, she still tried her best to serve the spirit, though she seemed almost cannot handle the smell from the spirit.

Although Chihiro's self-reliance has increased, she still obeyed most of the rules of the bath house and of the spirit world, even though she broke it twice. But she broke it for a very good reason, which was to save Haku and her parents. Her love for her parents and for Haku was enormously big, which made her willingly and unhesitatingly put her life in the line of fire in order to save them. How Chihiro loved Rin and Kamaji, cared for Bou, and grateful for Yubaba and Zeniba, and of course vice versa, has become assets for the cultivation of the family spirit. The word "family" here not only refers to whom has blood relationship, but much wider which covered the people in our everyday life; who we live with, who we interact with, and who we bound to.

\section{Conclusions}

In Spirited Away, Chihiro has shown us that her actions have met the four groups of desirable habits with its four groups of recommended traits, as written in moral education for the elementary school's guidance in the introduction section of this paper. Her actions are proof that she acts and reacts as what she taught in school, although she sometimes broke the rules which was natural for human being, especially for kids. Therefore, based on the findings on this paper only, it can be concluded that the Japanese government has succeeded in giving moral education in elementary school, at least in this anime. Actually, the well-structured Japanese moral education can be used in much wider place; not only in Japan but also in other countries as well, because it has universal human values recognized across 
cultures around the world, i.e. truthfulness, respect for other people, respect for the laws, and many others.

\section{References}

Anzai, S. (2014). Values and Value Priorities Underlying Japanese Elementary-School Moral Education: Content Analysis of Japanese Elementary-School Moral Books. Mediterranean Journal of Social Sciences, 5(4), 359-369. https://doi.org/10.5901/mjss.2014.v 5n4p359

Eagleton, T. (2013). How to Read Literature. https://doi.org/10.5860/choice.510702

Ghotbi, N. (2015). Religion, Moral Values and the Ethics of Japanese Society. Asia Pacific World, Vol. 6 No.(Spring 2015), 21-32.

Luhmer, K. (1990). Moral Education in Japan. Journal of Moral Education, (Vol. 19, No. 3), 172-181. https://doi.org/10.1080/0305724900 190303

Lullaby lyrics: Itsy-Bitsy Spider | BabyCenter. (n.d.). Retrieved June 9, 2020, from https://www.babycenter.com/0_lulla by-lyrics-itsy-bitsy-spider_6729.bc

Miyazaki, H. (2001). Spirited Away. Japan: Toho.

Napier, S. J. (2019). The Problem of Existence in Japanese Animation. Proceedings of the American
Philosophical Society, 149(1), 72-79. Retrieved from https://www.jstor.org/stable/459891 $0 \% 0 \mathrm{~A}$

Noviana, F. (2018). Adaptasi Cerpen Chuumon no Ooi Ryouri Ten Karya Miyazawa Kenji Menjadi Anime Karya Shibuichi Setsuko. Japanese Research on Linguistics, Literature, and Culture, 1(1), 1-15. https://doi.org/10.33633/jr.v1i1.213 1

Noviana, F. (2019). Representasi Hero's Journey pada Tokoh Chihiro dalam Anime Spirited Away Karya Miyazaki Hayao. Izumi, 8(1), 52. https://doi.org/10.14710/izumi.8.1.5 2-64

Shore, L. A. (2014). The Anima in Animation: Miyazaki Heroines and Post-Patriarchal Consciousness (Pacifica Graduate Institute). Retrieved from http://easyaccess.lib.cuhk.edu.hk/log in?url=http://search.proquest.com/d ocview/1628095940?accountid=1037 1\%5Cnhttp://findit.lib.cuhk.edu.hk/8 52cuhk/?url_ver=Z39.882004\&rft_val_fmt=info:ofi/fmt:kev:m tx:dissertation\&genre=dissertations + \%26+theses\&sid=ProQ:P

Suan, S. (2013). The Anime Paradox: Patterns and Practices Through the Lens of Traditional Japanese Theater. https://doi.org/10.1163/9789004222 151

Swingewood, A., \& Laurenson, D. T. (1972). The Sociology of Literature. New York: Schocken Books Inc.

The universal language of lullabies - BBC News. (n.d.). Retrieved June 9, 2020, 
Available online di http://ejournal.undip.ac.id/index.php/humanika

from

https://www.bbc.com/news/magazin e-21035103

Wu, C. I. (2016). Hayao Miyazaki's Mythic Poetics: Experiencing the Narrative Persuasions in Spirited Away, Howl's
Moving Castle and Ponyo. Animation: An Interdisciplinary Journal, 11(2), 189-203.

https://doi.org/10.1177/1746847716 643777 